\title{
Inflammatory response to cardiac bypass in ewe fetuses: Effects of steroid administration or continuous hemodiafiltration
}

\author{
Adriano Carotti, $\mathrm{MD}^{\mathrm{a}}$ \\ Francesco Emma, MD \\ Stefano Picca, $M D^{b}$ \\ Enrico lannace, $\mathrm{MD}^{\mathrm{a}}$ \\ Sonia B. Albanese, $\mathrm{MD}^{\mathrm{a}}$ \\ Mauro Grigioni, $\mathrm{MS}^{\mathrm{c}}$ \\ Francesco Meo, $\mathrm{PhD}^{\mathrm{d}}$ \\ Mario Sciarra, $\mathrm{PhD}^{\mathrm{d}}$ \\ Roberto M. Di Donato, MD
}

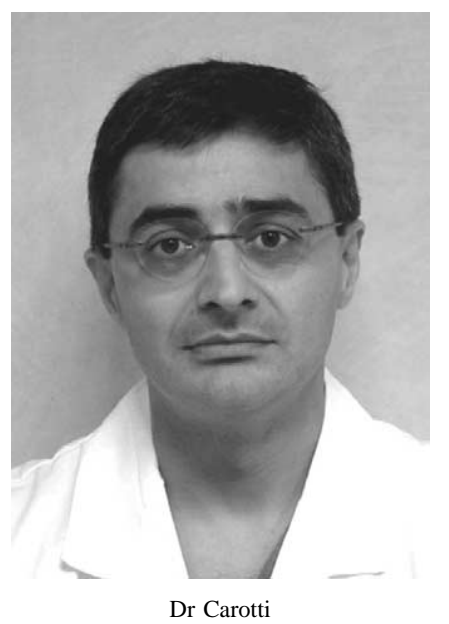

From the Departments of Pediatric Cardiology and Cardiac Surgery and Nephrology and Dialysis, ${ }^{\text {b }}$ Ospedale Bambino Gesu', Rome, Italy; the Laboratory of Biomedical Engineering, ${ }^{\mathrm{c}}$ Istituto Superiore di Sanità, Rome, Italy; and the Department of Anesthesiology, Intensive Care, and Emergency Medicine, ${ }^{\mathrm{d}}$ Universita' Cattolica del Sacro Cuore, Rome, Italy.

Read at the Eighty-third Annual Meeting of The American Association for Thoracic Surgery, Boston, Mass, May 4-7, 2003.

Received for publication April 25, 2003; accepted for publication June 18, 2003.

Address for reprints: Adriano Carotti, MD, Department of Pediatric Cardiology and Cardiac Surgery, Ospedale Bambino Gesu' I.R.C.C.S., Piazza S. Onofrio, 4, 00165 Rome, Italy (E-mail: carotti@opbg.net).

J Thorac Cardiovasc Surg 2003;126:1839-50

Copyright $\odot 2003$ by The American Association for Thoracic Surgery

$0022-5223 / 2003 \$ 30.00+0$

doi:10.1016/S0022-5223(03)01293-5
Objectives: We sought to investigate the effectiveness of glucocorticoid administration or continuous venovenous hemodiafiltration on endothelin and corticotropinreleasing factor release or clearance during prolonged fetal cardiac bypass and on the overall performance of fetuses.

Methods: Circulating endothelin 1, 2, and 3 and corticotropin-releasing factor levels were measured in fetal ewes during a 60-minute cardiac bypass period performed with an inline axial flow pump. Blood samples were collected before, during, and 90 minutes after cardiac bypass. Animals were divided into 4 groups. The betamethasone group $(\mathrm{n}=6)$ received maternal treatment with $12 \mathrm{mg}$ of betamethasone 1 and 2 days before the experiment. The methylprednisolone group $(n=5)$ received fetal treatment with $40 \mathrm{mg} / \mathrm{kg}$ intravenous methylprednisolone at the beginning of cardiac bypass. The continuous venovenous hemodiafiltration group $(n=4)$ underwent continuous venovenous hemodiafiltration with a $0.3-\mathrm{m}^{2}$ polysulfone filter during cardiac bypass. The final group was the control group $(n=4)$.

Results: Maternal steroid pretreatment failed to decrease endothelin or corticotropin-releasing factor production when compared with levels in the control animals. Fetal treatment with methylprednisolone produced a significant decrease in endothelin 2 production during cardiac bypass $(P<.02)$ and endothelin 1 production at the end of the experiment $(P<.02)$. Continuous venovenous hemodiafiltration blocked completely the increase of endothelin and corticotropin-releasing factor levels during cardiac bypass $(P<.02)$, which was maintained 90 minutes after cardiac bypass. Acid-base balance was preserved during cardiac bypass by the continuous venovenous hemodiafiltration but worsened after disconnection of the extracorporeal circuit, whereas animals treated with methylprednisolone had better $\mathrm{pH}, \mathrm{PaCO}_{2}$, and bicarbonate levels by the end of the experiment. The overall tolerance of the procedure was better in the continuous venovenous hemodiafiltration group during cardiac bypass and in the methylprednisolone group at the end of the experiment.

Conclusions: Continuous venovenous hemodiafiltration provides sustained stability of endothelin levels during fetal cardiac bypass. This technique might help, in association with fetal steroid treatment, to contain the inflammatory response leading to postbypass placental dysfunction. 


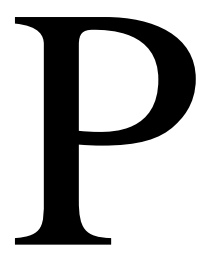

lacental dysfunction during experimental fetal cardiac surgery is a major obstacle to successful in utero extracorporeal cardiac bypass (CB). ${ }^{1-3}$ Released interleukins and other inflammatory or vasoactive substances have been shown to play an important role in the dysfunction of the fetoplacental unit during CB. ${ }^{4-6}$ Despite miniaturized extracorporeal circuits resulting in significantly improved fetal survival by reducing the extracorporeal surface and avoiding transfusion of blood components, inflammatory reactions and related fetoplacental dysfunctions still occur. ${ }^{7,8}$ Glucocorticoid agents administered before fetal $\mathrm{CB}$ have been shown to improve placental function. Possible involved mechanisms include inhibition of vasoconstrictive prostaglandin production and inhibition of proinflammatory cytokine synthesis. ${ }^{9,10}$ In recent years, hemofiltration techniques have been diffusely adopted during pediatric cardiopulmonary bypass to reduce the inflammatory response to the bypass itself, to help clear circulating cytokines produced during the procedure, or both. ${ }^{11-16}$

On these bases, we have conducted experiments to analyze the effect of glucocorticoid administration and continuous venovenous hemodiafiltration (CVVHD) on endothelin and corticotropin-releasing factor (CRF) plasma concentrations during prolonged fetal $\mathrm{CB}$ and on the overall performance of the fetoplacental unit function during and after the procedure. The experimental set-up included a 60-minute period of fetal CB performed by using a miniaturized circuit with an inline axial flow pump without an extracorporeal oxygenator, followed by a 90-minute observation period.

\section{Methods}

\section{Animals}

Animals were divided into 4 groups. In the betamethasone group $(n=6)$ pregnant ewes were pretreated with 2 doses of $12 \mathrm{mg}$ of intramuscular betamethasone 1 and 2 days, respectively, before the experiment. In the methylprednisolone group $(n=5)$ fetuses received a bolus of $40 \mathrm{mg} / \mathrm{kg}$ intravenous methylprednisolone just before CB. In the CVVHD group $(n=4)$ CVVHD was performed during the entire $\mathrm{CB}$. The final group was the control group $(\mathrm{n}=$ 4).

\section{Surgical Procedure}

Nineteen pregnant Comisana ewes between 120 and 130 days of gestation were fasted for 36 to 48 hours and premedicated by means of intramuscular injection with $10 \mathrm{mg} / \mathrm{kg}$ ketamine, 0.01 $\mathrm{mg} / \mathrm{kg}$ buprenorphine, and $0.02 \mathrm{mg} / \mathrm{kg}$ atropine. Induction of anesthesia was achieved with $2 \%$ inspired halothane supplied through a mask with a Fluotec vaporizer (Ohmeda Heath Care, West Yorkshire, England). After endotracheal intubation, epidural anesthesia was performed with $0.3 \mathrm{mg} / \mathrm{kg}$ of a $1 \%$ tetracaine hydrochloride solution. Anesthesia was then maintained with con- tinuous intravenous infusion of ketamine at a rate of $5 \mathrm{mg} \cdot \mathrm{kg}^{-1}$ $\cdot \mathrm{h}^{-1}$. Ewes were slightly hyperventilated with $100 \%$ oxygen to maintain $\mathrm{PaCO}_{2}$ blood gas levels at less than $30 \mathrm{~mm} \mathrm{Hg}$. Intraarterial and intravenous access were obtained to monitor maternal arterial blood pressure and blood gases and to infuse fluids during the surgical procedures.

The uterus was exposed through an extended midline laparotomy, and the number and orientation of the fetus or fetuses was determined. A short hysterotomy was made at the level of the upper chest of the selected fetus. The right forelimb was then extracted to cannulate a peripheral vein. Intravenous fetal anesthesia was then started with a bolus of ketamine $(10 \mathrm{mg} / \mathrm{kg})$ and maintained with an infusion of ketamine $\left(12 \mathrm{mg} \cdot \mathrm{kg}^{-1} \cdot \mathrm{h}^{-1}\right)$.

After exposure of the sternum, an extended midline sternotomy was performed. The right common carotid artery was dissected and cannulated for monitoring fetal arterial blood pressure and heart rate and for blood sampling. The right internal jugular vein was cannulated to infuse fluids at a constant rate of $20 \mathrm{~mL} \cdot \mathrm{kg}^{-1} \cdot \mathrm{h}^{-1}$. The pericardium was then opened, and purse-string sutures were placed on the main pulmonary artery and on the right appendix.

Heparin $(300 \mathrm{U} / \mathrm{kg}$ ) was administered intravenously before arteriovenous cannulation with a $16 \mathrm{~F}$ angled-tip venous cannula and a $3.5-\mathrm{mm}$ arterial cannula, both primed by means of retrograde fetal blood filling. The arterial and venous cannulae were then connected to a miniaturized bypass circuit by using an inline axial flow pump (Hemopump, modified model HP24 sternotomy pump; Medtronic Inc, Grand Rapids, Mich), and the CB was run at a flow rate of $300 \mathrm{~mL} \cdot \mathrm{kg}^{-1} \cdot \mathrm{min}^{-1}$ up to a maximal flow of $1 \mathrm{~L} / \mathrm{min}$ (see Appendix A).

After 60 minutes, the bypass was discontinued, the pulmonary arterial cannula was removed, and the priming volume was reinfused through the venous cannula. The atrial cannula was then removed. Heparin was not reversed.

After 90 minutes off pump, the experiment was terminated. The ewe and fetus were killed with an overdose $(200 \mathrm{mg} / \mathrm{kg})$ of intravenous sodium pentobarbital. Fetuses were then weighed to control the initial fetal weight estimation.

All animals received humane care in compliance with the Guide for the Care and Use of Laboratory Animals of the Italian Ministry of Health.

\section{CVVHD}

Fetuses of group 3 were treated with CVVHD without net ultrafiltration during the entire $\mathrm{CB}$ period. CVVHD was performed with a $0.3-\mathrm{m}^{2}$ polysulfone filter (Aquamax HF 03; Edwards Lifesciences, S.A., Saint-Prex, Switzerland) primed with 5\% human plasma protein solution. The system was connected in countercurrent with the bypass circuit to the venous arm. The blood flow rate was $150 \mathrm{~mL} / \mathrm{min}$, and the ultrafiltration balance was set to 0 . Blood flow and dialysis fluid balance were controlled by a BM 25 hemofiltration apparatus (Edwards Lifesciences). Fluid balance accuracy declared by the manufacturer is $\pm 0.5 \%$. HF 100 hemofiltration solution (Gambro S.p.a, Parma, Italy) was used at a flow rate of $4500 \mathrm{~mL} / \mathrm{h}$, containing $140 \mathrm{mmol} / \mathrm{L} \mathrm{Na}, 1.5 \mathrm{mmol} / \mathrm{L} \mathrm{K}, 2$ $\mathrm{mmol} / \mathrm{L} \mathrm{Ca}, 0.75 \mathrm{mmol} / \mathrm{L} \mathrm{Mg}, 108 \mathrm{mmol} / \mathrm{L} \mathrm{Cl}, 4 \mathrm{mmol} / \mathrm{L} \mathrm{CH}_{3}, 35$ $\mathrm{mmol} / \mathrm{L} \mathrm{HCO}_{3}$, and $5.55 \mathrm{mmol} / \mathrm{L}$ glucose. 
TABLE 1. Scoring table for overall performance definition

\begin{tabular}{|c|c|c|c|c|c|c|c|}
\hline Score & $\mathrm{pH}$ & $\mathrm{PaCO}_{2}(\mathrm{~mm} \mathrm{Hg})$ & $\mathrm{HCO}_{3}{ }^{-}(\mathrm{mmol} / \mathrm{L})$ & $\mathrm{O}_{2}$ Sat $(\%)$ & Lactate (mmol/L) & SBP (mm Hg) & DBP (mm Hg) \\
\hline 1 & $<7.10$ & $>60$ & $<20$ & $<30$ & $>12$ & $<40$ & $<30$ \\
\hline 2 & $7.10-7.20$ & $51-60$ & $20-22$ & $30-45$ & $10-12$ & $40-50$ & $30-35$ \\
\hline 3 & $7.21-7.30$ & $41-50$ & $23-25$ & $46-60$ & $7-9$ & $51-60$ & $36-40$ \\
\hline 4 & $7.31-7.40$ & $30-40$ & $26-28$ & $61-75$ & $4-6$ & $61-70$ & $41-45$ \\
\hline 5 & $>7.40$ & $<30$ & $>28$ & $>75$ & $<4$ & $>70$ & $>45$ \\
\hline
\end{tabular}

Range of values and related scores are reported for each parameter used, including arterial $\mathrm{pH}, \mathrm{PaCO}_{2}, \mathrm{HCO}_{3}{ }^{-}$, arterial oxygen saturation $\left(\mathrm{O}_{2} \mathrm{Sat}\right)$, lactate blood level, systolic arterial blood pressure $(S B P)$, diastolic arterial blood pressure $(D B P)$.

\begin{abstract}
Data Acquisition
Maternal and fetal heart rates and arterial blood pressures (Truwave PX-600F pressure transducers, Edwards Lifesciences) were monitored continuously during the entire study. Fetal hemodynamic parameters were recorded after heparin administration, before positioning the bypass cannulae (T0), during $\mathrm{CB}$ at 30 and 60 minutes (T30 and T60), and 30, 60, and 90 minutes after bypass was discontinued (T90, T120, and T150). One milliliter of fetal blood for gas, hemoglobin, hematocrit, electrolyte, glucose, and lactate analysis was drawn from the fetal carotid artery at the same time points and analyzed immediately with a Stat Profile Ultra analyzer (Nova, Waltham, Mass). Three milliliters of arterial blood for detection of endothelins 1, 2, and 3 and CRF plasma levels were sampled at $\mathrm{T} 0, \mathrm{~T} 60$, and $\mathrm{T} 150$; placed on ice in tubes containing $100 \mu \mathrm{L}$ of ethylenediamine tetraacetic acid; and immediately centrifuged at $5000 \mathrm{~g}$ for 10 minutes. The plasma fraction was then stored at $-70^{\circ} \mathrm{C}$ until assayed. For the analysis, samples were treated with an equal volume of $0.1 \%$ trifluoroacetic acid and centrifuged at $1000 \mathrm{~g}$ for 20 minutes, and the supernatant was analyzed in triplicate by using enzyme immunoassay kits for endothelins 1, 2, and 3 and CRF (Peninsula Laboratories Inc, San Carlos, Calif). Pilot experiments did not show a significant difference in the results, with plasma samples extracted with C18 SEP columns (data not shown). Endothelins and CRF were also measured in specimens obtained from the CVVHD dialysate fluid.
\end{abstract}

\section{Data Analysis}

Data are expressed as means $\pm \mathrm{SD}$ in the text and means $\pm \mathrm{SE}$ in figures.

Data analysis was performed with nonparametric tests because of the limited number of cases per group, which prevented analysis of normality, by using the SPSS statistical package 8.0 (SPSS Inc, Chicago, Ill). Statistical analysis to assess differences between groups was performed in 2 steps. First, data were compared by using the Kruskal-Wallis nonparametric test. If significant differences were found, treatment groups were compared individually with the control group by using the Mann-Whitney $U$ test. Differences within groups at different time points were assessed with the Wilcoxon signed-rank test (see Appendix B). All tests are 2 sided.

To assess the overall tolerance of the procedure, we have developed a score ranging from 5 to 35 that cumulates metabolic and hemodynamic data from 7 different parameters, including arterial $\mathrm{pH}, \mathrm{PaCO}_{2}$, bicarbonate level $\left(\mathrm{HCO}_{3}-\right)$, arterial oxygen saturation, lactate blood level, systolic arterial blood pressure, and diastolic arterial blood pressure. The average score of each group was then calculated and used to compare groups (Table 1).

\section{Results}

Groups were homogeneous with respect to fetal body weight (group 1, $2.8 \pm 0.5 \mathrm{~kg}$; group 2, $2.4 \pm 0.7 \mathrm{~kg}$; group $3,3.1 \pm 0.7 \mathrm{~kg}$; group $4,2.4 \pm 0.2 \mathrm{~kg} ; P=$ not significant).

On the first analysis of data, we observed a substantial linear evolution of all analyzed parameters in all groups during and after CB. Results are therefore presented only at $\mathrm{T} 0$, at the end of CB (T60), and at the end of the experiment (T150) to simplify the presentation and reading of the data.

\section{Fetal Arterial Blood Gases}

pH. Data on $\mathrm{pH}$ levels are shown in Figure 1, A. Initial $\mathrm{pH}$ levels were comparable between groups. A significant decrease by the end of the experiment was apparent in all animals. Statistically significant differences compared with levels in control animals were found only in the CVVHD group during the $\mathrm{CB}$, where the average $\mathrm{pH}$ level increased significantly.

$\mathrm{PaCO}_{2}$. Data on $\mathrm{PaCO}_{2}$ are shown in Figure 1, B. Mean $\mathrm{PaCO}_{2}$ levels increased regularly during the experimental procedure. A significant increase in $\mathrm{PaCO}_{2}$ level at the end of the experiment, when compared with baseline values, was found in all groups (Appendix B).

$\mathrm{HCO}_{3}{ }^{-}$. Data on $\mathrm{HCO}_{3}{ }^{-}$levels are shown in Figure 1, C. Mean $\mathrm{HCO}_{3}{ }^{-}$levels at T0 were comparable between groups. Maternal pretreatment with betamethasone appeared to cause a decrease in circulating $\mathrm{HCO}_{3}{ }^{-}$levels that became statistically different from that seen in control animals at both the end of the $\mathrm{CB}$ period and the end of the experiment. In the CVVHD group $\mathrm{HCO}_{3}{ }^{-}$levels increased significantly during the CVVHD but decreased rapidly once the animals were disconnected from the circuit. Conversely, the methylprednisolone group showed significantly increased $\mathrm{HCO}_{3}{ }^{-}$levels by the end of the experiment compared with baseline values (Appendix B).

Arterial oxygen saturation. Data on arterial oxygen saturation are shown in Figure 1, D. Mean arterial oxygen 


\section{MATERNAL BETAMETHASONE}
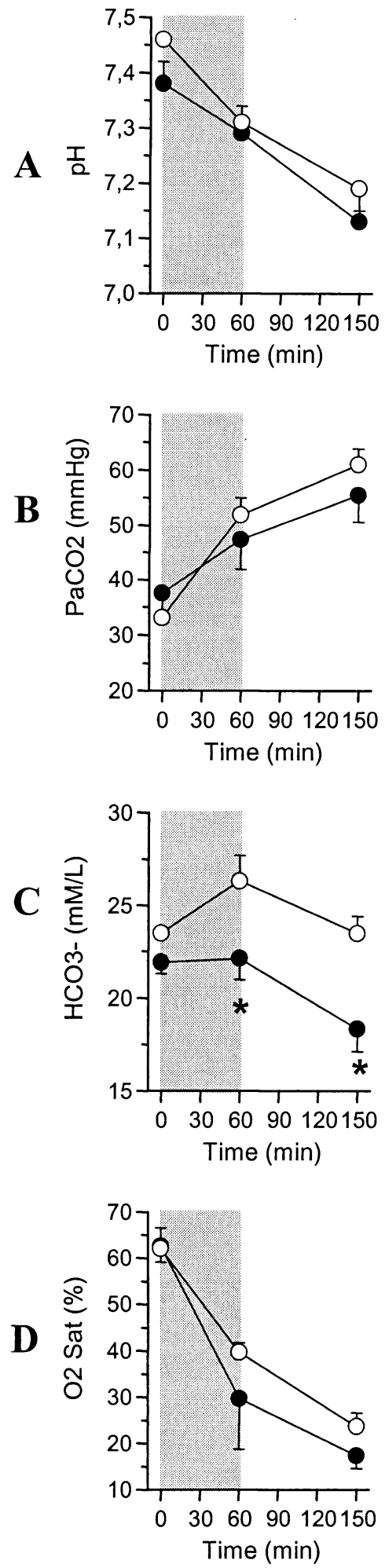
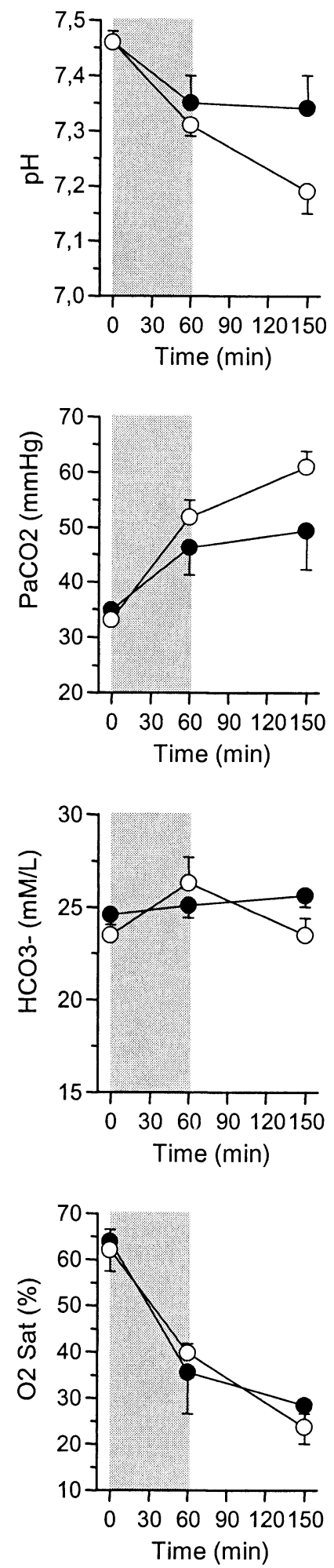

CVVHD
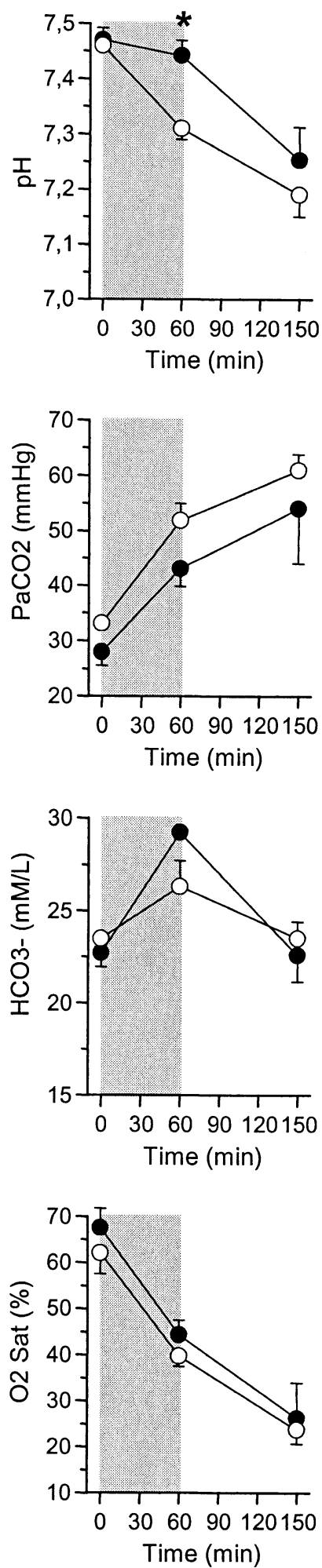

Figure 1. Fetal arterial blood gas trends expressed as means \pm SE. Open circles, control animals; filled circles, treatment groups; shaded area, CB; 02 Sat, arterial oxygen saturation. ${ }^{*} P<.05$ (Mann-Whitney $U$ test). 
saturation levels decreased to the same extent in all groups during the experiment. The maternal betamethasone group seemed to have the worst evolution compared with that seen in the control animals, but results did not reach statistical significance.

\section{Fetal Hemodynamics and Biochemicals}

Heart rate. Data on heart rate are shown in Figure 2, A. Initial and final average fetal heart rates were similar in all groups. Although not significantly, mean heart rate increased in all groups compared with in control animals during and at the end of the CB.

Systolic arterial blood pressure. Data on systolic arterial blood pressure are shown in Figure 2, B. Mean systolic arterial blood pressure was comparable at $\mathrm{T} 0$ in all groups. A significant increase was measured during $\mathrm{CB}$ in the betamethasone and methylprednisolone groups compared with in the control animals. Systolic blood pressure decreased significantly by the end of the $\mathrm{CB}$ compared with at baseline in the betamethasone and control groups (Appendix B).

Glucose blood level. Data on glucose blood levels are shown in Figure 2, C. Glucose levels increased throughout the $\mathrm{CB}$ in all groups. When compared with control animals, treated animals had less hyperglycemia.

Lactate blood level. Data on lactate blood levels are shown in Figure 2, $D$. The average lactate blood levels were comparable between all groups and increased significantly during the experiment, with the exception of the CVVHD group, in which lactate levels remained significantly stable during dialysis but increased thereafter.

\section{Endothelins and CRF Levels}

The mean plasma levels of endothelin 1 were similar at T0 in all groups and remained comparable with levels in control animals throughout the whole experiment in the betamethasone group. Endothelin 1 levels were significantly lower than those of control animals in the methylprednisolone group by the end of the experiment. Endothelin 1 levels remained comparable with baseline values in CVVHD-treated fetuses both during and after CB (Figure $3, A)$.

A similar trend was observed for endothelins 2 and 3 and CRF. All values were statistically different during and after CB in animals treated with CVVHD. Plasma endothelin 2 levels compared with levels in control animals were lower and reached statistical significance at the end of $C B$ in the methylprednisolone group (Figure 3, $B-D$ ).

Endothelins and CRF were not detected in the dialysate fluid from fetuses of the CVVHD group.

\section{Overall Performance Assessment Score}

A score was developed that included both hemodynamic and metabolic parameters to rank groups according to their overall performance during and after CB (see the "Methods" section). On the basis of this score, it appears that CVVHD-treated animals performed better during CB but worsened rapidly after discontinuation of the procedure. Methylprednisolone-treated animals had the best score by the end of the experiment (Figure 4).

\section{Discussion}

This study was designed to investigate the effect of steroid treatment and CVVHD on fetal tolerance of CB and the associated inflammatory response.

Inflammatory reaction during fetal $\mathrm{CB}$ has been shown to produce fetoplacental dysfunction either directly through neutrophil degranulation or mediated by interleukins and other vasoactive substances produced after endothelial damage. ${ }^{4-6,17}$ Pharmacologic agents, such as indomethacin and high-dose steroids, administered before fetal CB have been shown by Sabik and colleagues ${ }^{9,18}$ to improve placental function at least in part by inhibiting the production of vasoconstrictive prostaglandins.

The anti-inflammatory effect of glucocorticoids is also well known and is regularly used during cardiopulmonary bypass in clinical practice. ${ }^{10}$

In recent years, hemofiltration techniques during cardiopulmonary bypass have been diffusely adopted in pediatric cardiac surgery ${ }^{11-13}$ to reduce the inflammatory response to the bypass itself or to help clearing circulating cytokines produced during the procedure. ${ }^{14-16}$ It has been shown that hemofiltration can remove a wide variety of cytokines, most likely by means of absorption rather than filtration across the membrane. ${ }^{19-21}$

Our experimental set-up was planned to test directly whether steroids, CVVHD, or both are efficient in improving the tolerance to fetal $\mathrm{CB}$ and in decreasing the associated inflammatory reaction. Moreover, CVVHD could also be beneficial in preventing metabolic imbalances that develop during $\mathrm{CB}$.

Steroids were administered either to pregnant ewes 1 and 2 days before the experiment on the basis of protocols used to promote fetal lung maturation in clinical practice or to the fetuses before CB.

$\mathrm{CB}$, which has been shown to cause a marked release of endothelins in previous studies, ${ }^{6,22}$ was maintained for 60 minutes. The postbypass observation period was extended to 90 minutes to evaluate the long-term tolerance and effects of the various treatment regimens.

The miniaturized inline axial flow pump circuit significantly reduces the extracorporeal surface and priming but does not include an oxygenator. ${ }^{8}$ Despite the preservation of fetal placental circulation, the absence of an oxygenator 


\section{MATERNAL BETAMETHASONE}

A

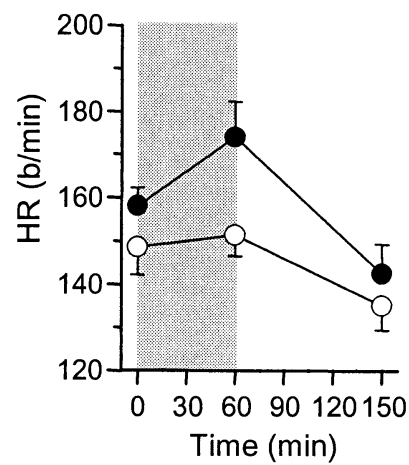

B

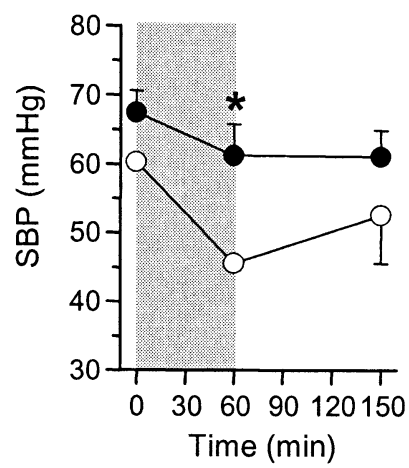

C

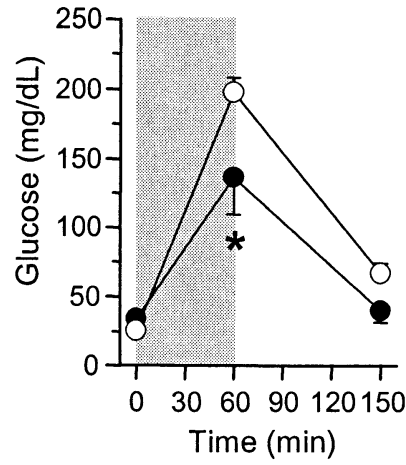

D

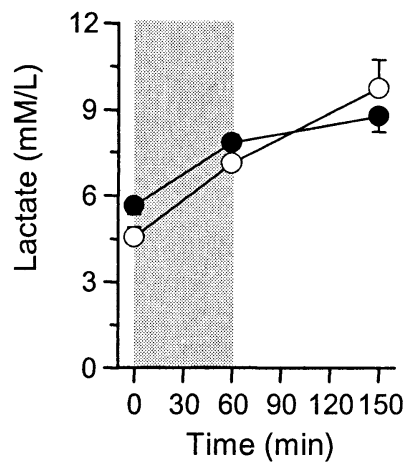

METHYLPREDNISOLONE
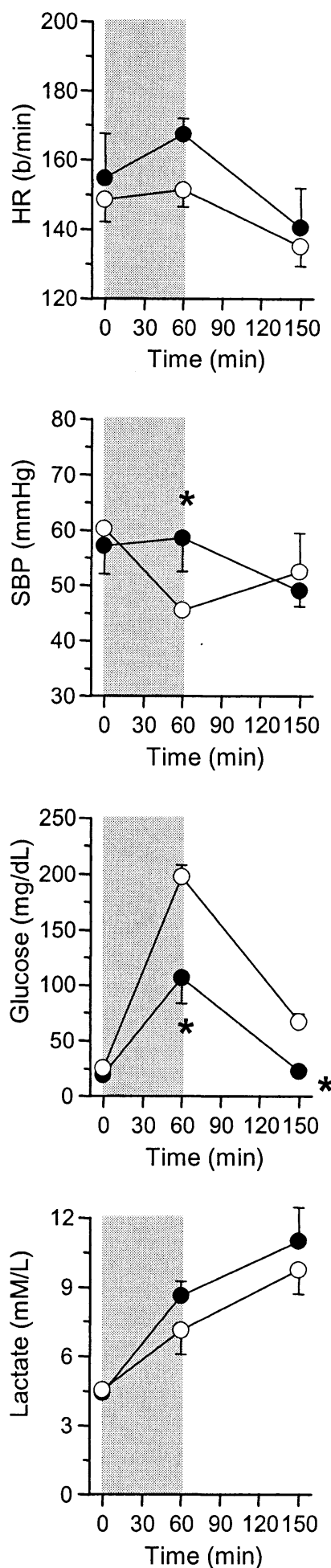

CVVHD
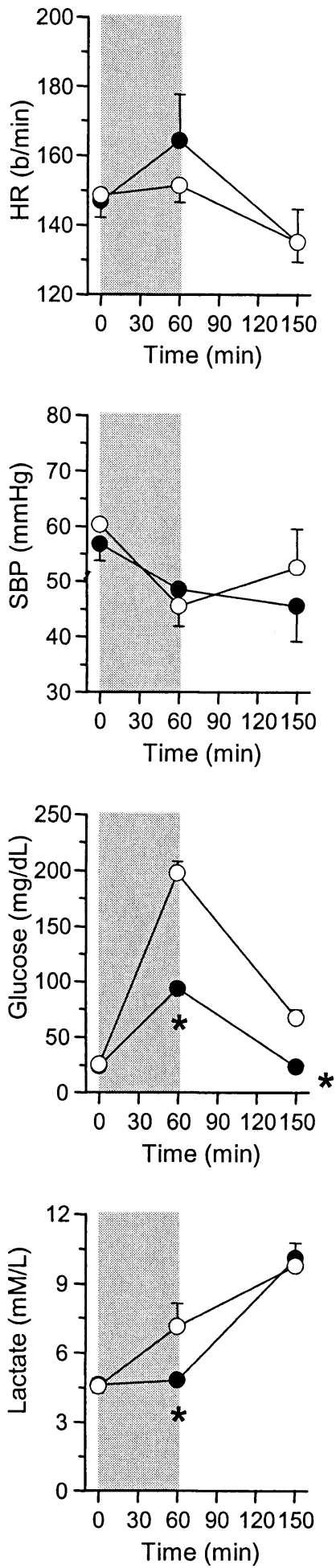

Figure 2. Fetal hemodynamic and biochemical trends expressed as means \pm SE. Open circles, control animals; filled circles, treatment groups; shaded area, $\mathrm{CB}$; $H R$, heart rate; $S B P$, systolic arterial blood pressure; glucose, glucose blood level; lactate, lactate blood level. ${ }^{*} P<.05$ (Mann-Whitney $U$ test). 


\section{MATERNAL \\ BETAMETHASONE}

A
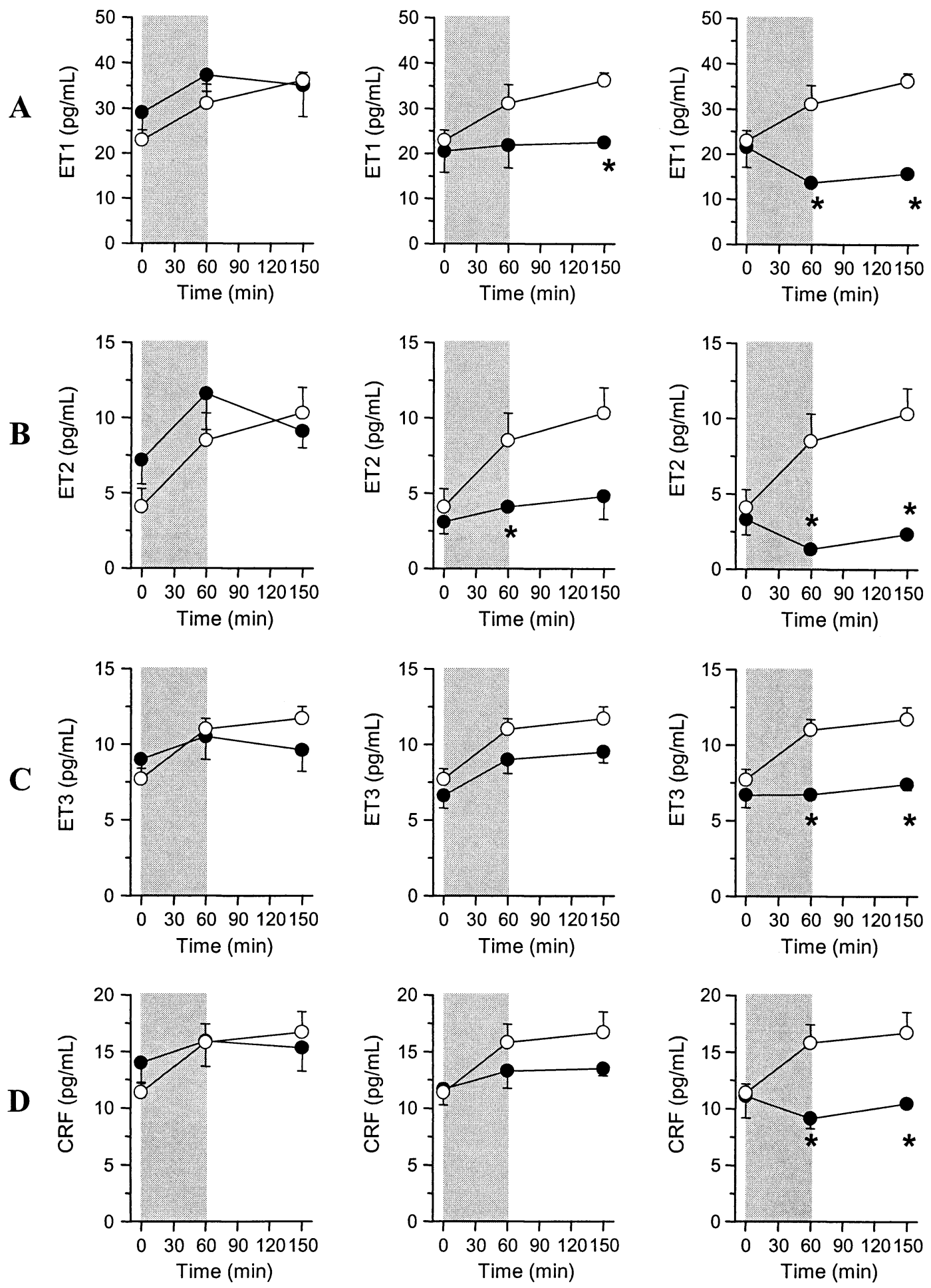

Figure 3. Fetal trends of plasma levels of vasoactive peptides expressed as means $\pm \mathrm{SE}$. Open circles, control animals; filled circles, treatment groups; shaded area, $\mathrm{CB}$; ET, endothelin. ${ }^{*} P<.05$ (Mann-Whitney $U$ test). 


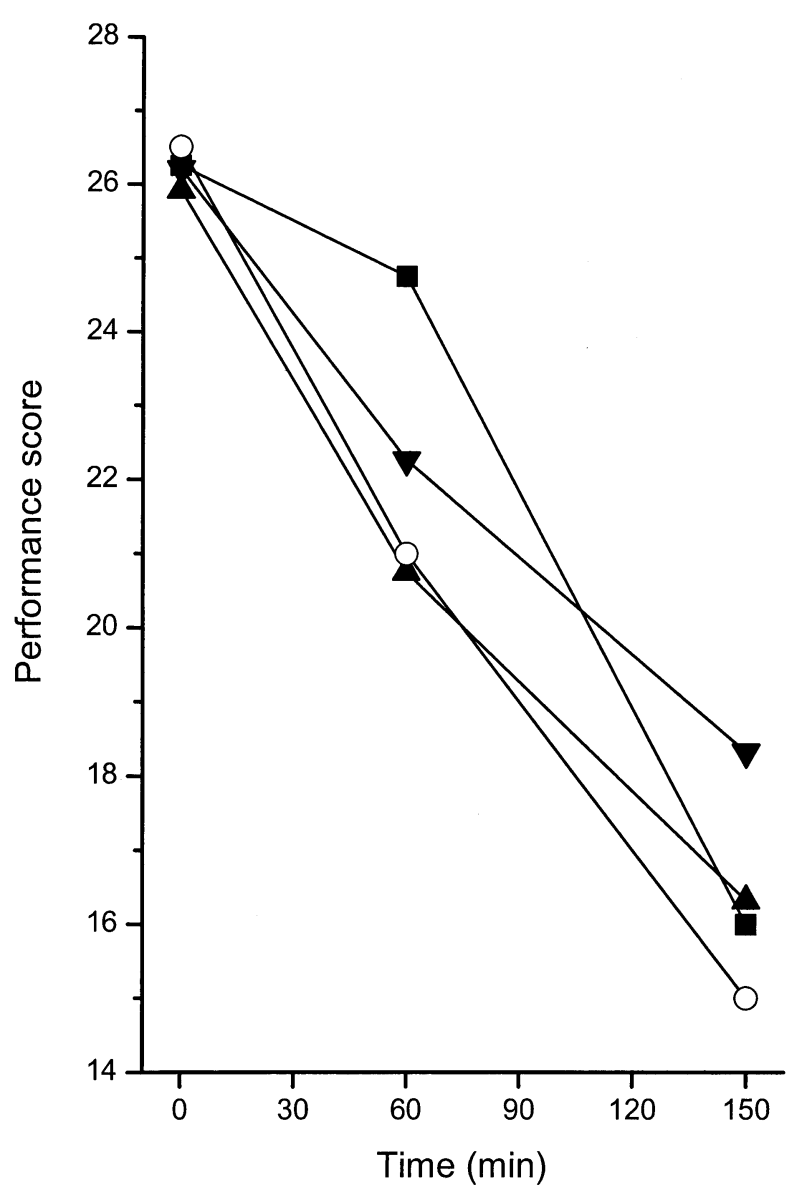

Figure 4. Performance score analysis that cumulates metabolic and hemodynamic data from 7 different parameters, including arterial $\mathrm{pH}, \mathrm{PaCO}_{2}$ (millimeters of mercury), $\mathrm{HCO}_{3}{ }^{-}$(millimoles per liter), arterial oxygen saturation (percentage), lactate blood level (millimoles per liter), systolic arterial blood pressure (millimeters of mercury), and diastolic arterial blood pressure (millimeters of mercury). Open circles, control animals; triangles, maternal pretreatment with betamethasone; inverted triangles, fetal treatment with methylprednisolone; filled squares, fetal CVVHD.

during prolonged $\mathrm{CB}$ has most likely increased fetal oxygen desaturation in our animals, which might have influenced the overall tolerance of the procedure.

The inflammatory reaction was monitored by dosing circulating plasma endothelins, which are produced on stimulation by proinflammatory cytokines. ${ }^{23,24}$ The analysis of other inflammatory and vasoactive mediators was limited by the lack of commercially available detection kits that crossreact with ewe peptides. Among these, CRF was chosen because it has been shown to be a potent human placental vasodilator through nitric oxide synthesis and release ${ }^{25}$ and because its production might have been influenced by maternal or fetal steroid therapy. In particular, it has been shown that maternal corticosteroid treatment suppresses hy- pothalamic CRF secretion but increases placental CRF production in vitro ${ }^{26}$ and in vivo, ${ }^{27}$ which is thought to promote placental vasodilation and subsequent reactive increase in fetal arterial blood pressure. ${ }^{28}$ These effects might be counterbalanced by a reduction in fetal $\mathrm{PaO}_{2}$ caused by maternal steroid treatment, as shown experimentally in sheep. ${ }^{29}$

The interpretation of our data has some limitations because they are obtained from a limited number of cases that often yielded clear trends in evolution without reaching statistical differences. These limitations are difficult to overcome because of the complexity of the experimental setting, which does not allow for using a large number of animals. To overcome these limitations, at least in part, we have developed a scoring system that includes a number of parameters known to be good estimators of the tolerance to $\mathrm{CB}$ stress. These data show that fetal CB was best tolerated during the bypass by CVVHD-treated animals but that animals treated with methylprednisolone performed better 90 minutes after the end of the procedure.

Maternal steroid pretreatment was ineffective and even deleterious to the fetoplacental unit. Higher fetal arterial blood pressure and heart rate during $\mathrm{CB}$, after $\mathrm{CB}$, or both and worse blood gases since the onset of the procedure in these fetuses compared with in control animals might result directly from maternal glucocorticoid treatment. ${ }^{29} \mathrm{CRF}$ levels did not differ significantly from those of the control group and were not influenced by maternal treatment. Apparently, worse hemodynamics at the beginning of the study might have also influenced the initial tolerance of the procedure in these animals.

Fetuses treated with methylprednisolone appeared to maintain better acid-base balance and arterial blood pressure throughout the experiment when compared with control animals, which probably reflects a better preservation of the fetoplacental unit after fetal steroid administration.

In the CVVHD group $\mathrm{pH}$ and bicarbonate levels were well preserved during the $\mathrm{CB}$ by the dialytic effect of CVVHD but decreased rapidly after the extracorporeal circulation was discontinued. In this respect CVVHD appeared to mask signs of placental dysfunction that might have been caused by worse hemodynamics. In fact, despite the fact that the CVVHD apparatus was mounted in countercurrent to the $\mathrm{CB}$ line, the pump appeared to be performing at a somewhat lesser level (loss of 20\%-30\% of the maximal flow rate), possibly because of the higher compliance of the system. In addition, partial hemodilution by the filter and tubing priming volume and poor immunologic tolerance to the human plasma protein solution that was used for priming might have contributed to the hemodynamic deterioration of this group of animals. Hemodilution, as assessed on the basis of hematocrit values, did not exceed $6 \%$ and was not statistically different from that of control fetuses (data not shown). 
The average blood glucose levels increased significantly throughout CB within each group and decreased thereafter to return to near-baseline values. The initial trend can be attributed to fetal stress and was higher in the control group when compared with that in the methylprednisolone and CVVHD groups. The mean blood lactate levels were comparable between groups and increased progressively throughout the experiment, with the exception of the CVVHD group, in which lactate levels remained stable during dialysis but increased thereafter. Overall, progressive lactate accumulation reflects increased anaerobic metabolism and correlates well with the decrease in oxygen saturation. Because lactate diffuses readily across the polysulfone filter, the initial lactate stability in the CVVHD group is likely to be caused by increased lactate clearance rather then decreased production. This is also re-enforced by the fact that these animals experienced a similar arterial desaturation when compared with the other animals. Similarly, blood glucose levels might have been balanced by the dialysate solution glucose levels in the CVVHD group, partially masking the hyperglycemic stress reaction to the CB.

The analysis of plasma endothelins and CRF levels showed that maternal steroid pretreatment failed to decrease the inflammatory release of these molecules. Fetal treatment with methylprednisolone produced a moderate but significant decrease of endothelin 2 production during $\mathrm{CB}$ and endothelin 1 production at the end of the experiment, supporting the efficacy of glucocorticoids in blocking proinflammatory cytokine production and secondary synthesis of endothelins. ${ }^{10,23,24}$

In control animals, but not in steroid-treated fetuses, circulating endothelins also continued to accumulate after discontinuation of the $\mathrm{CB}$, suggesting the activation of an inflammatory loop.

Most significantly, however, we found a complete suppression of endothelin accumulation in CVVHD fetuses that was well maintained after discontinuation of the CB. On the basis of the molecular weight and experimental data, some believe that clearance of these molecules is achieved primarily by absorption rather than a clearance across the membrane. ${ }^{19-21}$ In fact, we were not able to detect endothelins or CRF in the dialysate fluid, but these results are hampered by the dilution in the volume of the dialysate, which prevented accurate measurements at less than the limits of detection of our assay.

Our data suggest that polysulfone membranes can clear or inhibit the production of inflammatory and vasoactive peptides from the bloodstream. Noticeably, however, clearance by means of absorption is highly enhanced by the use of net ultrafiltration forces, which we did not use. Taken together with the fact that we did not observe a rebound of endothelin accumulation after discontinuation of the CVVHD, it is possible that polysulfone membranes might have been sufficient to remove even small amounts of molecules produced in the initial phases of the reaction to the $\mathrm{CB}$ and therefore have blocked the initiation of an inflammatory amplification loop. Alternatively, polysulfone membranes might have directly decreased production of inflammatory mediators by stabilizing circulating inflammatory cells that are otherwise activated through their passage into the extracorporeal circuit. This point deserves further investigation.

\section{Conclusion}

CVVHD provides sustained stability of plasma levels of vasoactive substances during fetal $\mathrm{CB}$. This technique might help, possibly in association with fetal steroid treatment, to contain the inflammatory response leading to postbypass placental dysfunction, which has been shown to be crucial to allow future feasibility of open fetal cardiac surgery.

\section{References}

1. Bradley SM, Hanley FL, Duncan BW, Jennings RW, Jester JA, Harrison $\mathrm{MR}$, et al. Fetal cardiac bypass alters regional blood flows, arterial gases, and hemodynamics in sheep. Am J Physiol Heart Circ Physiol. 1992;263:H919-28.

2. Hawkins JA, Clark SM, Shaddy RE, Gay WA Jr. Fetal cardiac bypass: improved placental function with moderately high flow rates. Ann Thorac Surg. 1994;57:293-7.

3. Fenton KN, Heinemann MK, Hickey PR, Klautz RJ, Liddicoat JR, Hanley FL. Inhibition of the fetal stress response improves cardiac output and gas exchange after fetal cardiac bypass. J Thorac Cardiovasc Surg. 1994;107:1416-22.

4. Reddy VM, McElhinney DB, Rajasinghe HA, Rodriguez JL, Hanley FL. Cytokine response to fetal cardiac bypass. J Matern Fetal Investig. 1998;8:46-9.

5. Parry AJ, Petrossian E, McElhinney DB, Reddy VM, Hanley FL. Neutrophil degranulation and complement activation during fetal cardiac bypass. Ann Thorac Surg. 2000;70:582-9.

6. Reddy VM, McElhinney DB, Rajasinghe HA, Liddicoat JR, Hendricks-Munoz K, Fineman JR, et al. Role of the endothelium in placental dysfunction after fetal cardiac bypass. J Thorac Cardiovasc Surg. 1999;117:343-51.

7. Reddy VM, Liddicoat JR, Klein JR, Wampler RK, Hanley FL. Longterm fetal outcome after cardiac bypass: fetal survival to full term and organ abnormalities. J Thorac Cardiovasc Surg. 1996;111:536-44.

8. Reddy VM, Liddicoat JR, Klein JR, McElhinney DB, Wampler RK, Hanley FL. Fetal cardiac bypass using an in-line axial flow pump to minimize extracorporeal surface and avoid priming volume. Ann Thorac Surg. 1996;62:393-400.

9. Sabik JF, Heinemann MK, Assad RS, Hanley FL. High-dose steroids prevent placental dysfunction after fetal cardiac bypass. J Thorac Cardiovasc Surg. 1994;107:116-25.

10. El Azab SR, Rosseel PM, de Lange JJ, Groeneveld AB, van Strik R, van Wijk EM, et al. Dexamethasone decreases the pro- to antiinflammatory cytokine ratio during cardiac surgery. $\mathrm{Br} J$ Anaesth. 2002;88:496-501.

11. Naik SK, Knight A, Elliott M. A prospective randomized study on modified technique of ultrafiltration during pediatric open-heart surgery. Circulation. 1991;84:422-31.

12. Andreasson S, Gothberg S, Berggren H, Bengtsson A, Eriksson E, Risberg B. Hemofiltration modifies complement activation after extracorporeal circulation in infants. Ann Thorac Surg. 1993;56:1515-7.

13. Elliott MJ. Ultrafiltration and modified ultrafiltration in pediatric open heart operations. Ann Thorac Surg. 1993;56:1518-22. 
14. Millar AB, Armstrong L, van der Linden J, Moat N, Ekroth R, Westwick J, et al. Cytokine production and hemofiltration in children undergoing cardiopulmonary bypass. Ann Thorac Surg. 1993;56:1499502 .

15. Journois D, Pouard P, Greeley WJ, Mauriat P, Vouhe P, Safran D. Hemofiltration during cardiopulmonary bypass in pediatric cardiac surgery: effects on hemostasis, cytokines and complement components. Anesthesiology. 1994;81:1181-9.

16. Journois D, Israel-Biet D, Pouard P, Rolland B, Silvester W, Vouhe P, et al. High-volume, zero-balanced hemofiltration to reduce delayed inflammatory response to cardiopulmonary bypass in children. Anesthesiology. 1996;85:965-76.

17. Adamson SL, Whiteley KJ, Langille BL. Endothelin-1 constricts fetoplacental microcirculation and decreases fetal $\mathrm{O} 2$ consumption in sheep. Am J Physiol Heart Circ Physiol. 1996;270:H16-23.

18. Sabik JF, Assad RS, Hanley FL. Prostaglandin synthesis inhibition prevents placental dysfunction after fetal cardiac bypass. $J$ Thorac Cardiovasc Surg. 1992;103:733-42.

19. Swinford RD, Baid S, Pascual M. Dialysis membrane adsorption during CRRT. Am J Kidney Dis. 1997;30(suppl 4):S32-7.

20. Cole L, Bellomo R, Davenport P, Tipping P, Uchino S, Tetta C, et al. The effect of coupled haemofiltration and adsorption on inflammatory cytokines in an ex vivo model. Nephrol Dial Transplant. 2002;17: 1950-6.

21. Kellum JA, Dishart MK. Effect of hemofiltration filter adsorption on circulating IL-6 levels in septic rats. Crit Care. 2002;6:429-33.

22. Vedrinne C, Tronc F, Martinot S, Robin J, Allevard A-M, Vincent M, et al. Better preservation of endothelial function and decreased activation of the fetal renin-angiotensin pathway with the use of pulsatile flow during experimental fetal bypass. J Thorac Cardiovasc Surg. 2000;120:770-7.

23. Woods M, Mitchell JA, Wood EG, Barker S, Walcot NR, Rees GM, et al. Endothelin-1 is induced by cytokines in human vascular smooth muscle cells: evidence for intracellular endothelin-converting enzyme. Mol Pharmacol. 1999;55:902-9.

24. Lüscher TF, Barton M. Endothelins and endothelin receptor antagonists. Therapeutic considerations for a novel class of cardiovascular drugs. Circulation. 2000;102:2434-40.

25. Clifton VL, Read MA, Leitch IM, Giles WB, Boura AL, Robinson PJ, et al. Corticotropin-releasing hormone-induced vasodilatation in the human fetal-placental circulation: involvement of the nitric oxidecyclic guanosine 3',5'-monophosphate-mediated pathway. J Clin Endocrinol Metab. 1995;80:2888-93.

26. Robinson BG, Emanuel RL, Frim DM, Majzoub JA. Glucocorticoids stimulate expression of corticotropin-releasing hormone gene in human placenta. Proc Natl Acad Sci U S A. 1988;85:5244-8.

27. Marinoni E, Korbrits C, Di Iorio R, Cosmi EV, Challis JRG. Effect of betamethasone in vivo on placental corticotropin-releasing hormone in human pregnancy. Am J Obstet Gynecol. 1998;178:770-8.
28. Wallace EM, Baker LS. Effect of antenatal bethamethasone administration on placental vascular resistance. Lancet. 1999;353:1404-7.

29. Bennet L, Kozuma S, McGarrigle HHG, Hanson MA. Temporal changes in fetal cardiovascular, behavioural, metabolic and endocrine responses to maternally administered dexamethasone in the late gestation fetal sheep. Br J Obstet Gynaecol. 1999;106:331-9.

\section{Appendix A. Perfusion Control}

An indirect method was used to monitor the pump efficiency and the perfusion condition on the basis of pressure measurements (pressure transducers Truwave PX-600 F, Edwards Lifesciences) in the bypass circuit upstream and downstream to the axial flow pump (Hemopump, modified model HP24 sternotomy pump; Medtronic Inc).

Assuming that the venous and arterial branches of the circuit represent preload and afterload for the pump, respectively, these loads constitute crucial settings to obtain the flow rate requested. To study the pump flow rates for any possible loading condition, an in vitro setup was designed to allow measurements of pump inlet and outlet pressures and also pressure decrease along the arterial cannula; a regression line was calculated from those data. A gravimetric method was used to set the preload between 3 and $6 \mathrm{~mm} \mathrm{Hg}$ and afterload in steps of $10 \mathrm{~mm} \mathrm{Hg}$ by means of 2 constant head tanks. Thus a steady flow setup was provided to determine pump efficiency within the same circuit used for fetal CB. All the 7-step speed levels of the pump were selected, and pressures and flows were recorded with pressure transducers (Transpack; Abbott Healthcare, Ithaca, NY) and an electromagnetic flowmeter (Handress \& Hauser Italia, Cernusco, Italy) with a $0.1 \%$ accuracy at the arterial outlet. According to a preliminary flow visualization of the pump function in a glass test bench, pressure transducers were placed in positions where no flow separation or vorticity occurred.

From these recordings, tables and functions were obtained to compare with the in vivo experimental data and to derive the perfusion flow rate on the basis of pump preload, afterload, and speed.

With the average mean right atrial pressure measured at the steady state during $\mathrm{CB}$ being $5 \mathrm{~mm} \mathrm{Hg}$ and the average mean systemic blood pressure being $45 \mathrm{~mm} \mathrm{Hg}$, the maximal flow rate obtained at the fastest pump speed was $1 \mathrm{~L} / \mathrm{min}$. 